\title{
Intermittent claudication among smokers
}

\author{
T. R. Yathish, ${ }^{1}$ N. Annamallai, ${ }^{2}$ V. Shankar ${ }^{2}$ \\ ${ }^{1}$ Department of physiology, Hassan Institute of Medical Sciences, Hassan-573201, Karnataka, India; ${ }^{2}$ Department of \\ physiology, Sri Devaraj Urs Medical College, Tamaka, Kolar-563101, Karnataka, India
}

Correspondence to: Dr. T. R Yathish, Department of physiology, Hassan Institute of Medical Sciences, Hassan-573201, Karnataka, India, (Mobile +919448410163)

Email: yathi_aradhya@yahoo.co.in

\begin{abstract}
Introduction: Peripheral artery disease with intermittent claudication is an important cause of morbidity and mortality. Cigarette smoking is thought to be major risk factor. Currently, up to $2 \%$ of all deaths are attributable to peripheral artery disease and its complication. The economic burden associated with peripheral artery disease is also substantial. There are still significant gaps in the current understanding of the epidemiology and burden of peripheral artery disease at the population level.

Methods: The aim of this study was to study intermittent claudication through survey by questionnaire method and to study risk factors of tobacco by evaluating the relationship between smokers and intermittent claudication using well accepted Rose intermittent claudication and smoking questionnaire method.

This observational, descriptive, cross-sectional study was conducted in the teaching hospital of R.L. Jalappa Hospital of Sri Devaraj Urs medical college, Tamaka, Kolar, Karnataka, India during January 2004 to July 2004. A total of 130 adult men above the age of 30 years who visited the hospital with pain in the lower limbs constituted the materials for the present study. They were categorized into smokers and non-smokers. Each case was examined for lower limbs in detail and their findings were noted.
\end{abstract}

Results: Participants in the group with leg pain on exertion and rest were nearly 92 . Among 90 smokers, 80 had the classic symptom of intermittent claudication which started in the third decade of life whereas out of 40 non-smokers, only 12 had intermittent claudication which started after the fifth decade of life.

Conclusions: Smoking not only results in early onset of intermittent claudication but also increases the risk of development of intermittent claudication by more than $80 \%$.

Keywords: Intermittent claudication, rose intermittent claudication and smoking questionnaire, smoking

\section{Introduction}

Smoking constitutes the single most important and effective risk factor. Smoking increases the risk for developing intermittent claudication by more than $80 \%$. Other risk factors associated with peripheral artery disease include older age, diet, nutritional status, hormonal status, cigarette smoking, diabetes mellitus, hypertension, hypercholesterolemia, and (possibly) genetic factors. ${ }^{1}$ There is a wide range of leg symptoms in persons with peripheral artery disease beyond that of classic intermittent claudication. Co-morbid disease may contribute to these symptoms in peripheral artery disease (PAD). Functional impairments are found in every peripheral artery disease symptom group, and the degree of functional limitation varies depending on the type of leg symptoms.

Atherosclerosis is the most common cause of chronic 
arterial occlusive disease of the lower extremities. Obstruction that occurs as a result of the atherosclerotic process reduces blood flow to the lower limb during exercise or at rest. ${ }^{2} \mathrm{~A}$ spectrum of symptoms results, the severity of which depends on the extent of the involvement and the available collateral circulation. Thus, symptoms may range from claudication to pain at rest. The pain is due to insufficient blood flow in the legs caused by blocked arteries. Ischemic pain in the leg muscles precipitated by walking and relieved by rest is known as intermittent claudication (IC). Claudication comes from the Latin word "claudicare" means "to limp." Claudication is crampy leg pain that occurs during exercise, especially walking. Symptoms may only initially be present when walking uphill, walking faster, or walking for longer distances.

Because the most frequently affected artery in intermittent claudication is the popliteal artery, symptoms are most common in the calf muscles. This artery leads off from the femoral artery (the major artery in the thigh). It continues below the knee where it branches off and carries blood to the muscles in the calf and foot. Patients may also have fatigue or pain in the thighs and buttocks.

Critical limb ischemia (CLI) is defined as rest (night) pain, requiring opiate analgesia, and/or tissue loss like ulceration or gangrene, present for more than 2 weeks, in the presence of an ankle blood pressure of less than $50 \mathrm{~mm} \mathrm{Hg}$. Rest pain and no tissue loss with ankle pressures above $50 \mathrm{mmHg}$ is sometimes known as subcritical limb ischemia (SCLI). The term severe limb ischemia (SLI) is often used to describe both entities. $^{2}$

The pulses in the legs and feet are evaluated on the clinical exam. Diagnostic tests include blood pressure measurements to compare the arms and legs, Doppler ultrasonography on the legs, duplex Doppler/ultrasound exam of the extremities to visualize arterial blood flow, and arteriography (injecting dye that can be visualized in the arteries).

With 'best medical therapy', only $1-2 \%$ per year will deteriorate to a point where amputation and/or revascularization are required. The annual mortality rate exceeds $5 \%$, which is $2-3$ times higher than an equivalent non-claudicant population. This excess mortality is due to the fact that intermittent claudication is nearly always found in association with widespread atherosclerosis. ${ }^{2}$

Advanced Peripheral Artery Disease (Ischemic Rest Pain):

In advanced cases, the arteries are so blocked that even rest does not help. Leg pain that continues when lying down is called ischemic rest pain. Typical symptoms may include:
- Pain or tingling in the foot or toes, which may be so severe that even the weight of clothes or bed sheets cause or worsen the discomfort

- Pain worsens when leg is elevated and improves by dangling legs over the side of the bed

People with ischemic rest pain are at risk for ulcers and gangrene. In severe cases, amputation may be required. Other signs of advanced PAD include:

- Calf muscles that shrink (wither)

- Hair loss over the toes and feet

- Thick toenails

- Shiny, tight skin

- Painful non-bleeding ulcers on the feet or toes (usually black) that are slow to heal

- Sometimes, blood clots form in the arteries in the legs, producing abrupt symptoms.

\section{Methods}

A total of 130 subjects constituted the materials for present study. They were above the age of 30 years. A written consent was taken and the patients were examined in detail with proper history. A detailed family history of diabetes mellitus, hypertension, coronary artery disease, chronic lung disease, and drug intake affecting cardiovascular system were taken along with personal history like drug history, history of smoking were recorded. Previous or current cigarette smoking was considered a positive smoking history. In the above patients, the number of cigarettes and their frequency were also noted.

130 male subjects were grouped as study group (smokers) and controls (non-smokers). Rose questionnaire was used as a tool to detect peripheral artery disease. The results were compared between the two groups.

The data obtained were arranged in a tabular form and discussed. Analysis was performed using SPSS 8.0 statistical package for windows. Continuous variables were expressed as the mean + standard deviation and qualitative data as percentages. Comparison of patients' features was performed using Student's t-test for unpaired data. Pearson's correlation coefficient test was carried out to know the correlation of smoking and intermittent claudication. Chi-square test was carried out to evaluate the significance of intermittent claudication in different groups. The mean difference was significant at $\mathrm{P}<0.05$ level. Conclusion was drawn based on the outcome of this statistical treatment. 


\section{Results}

Of the 130 participants, $90(70 \%)$ were smokers and $40(30 \%)$ were nonsmokers. The mean values in each age group, that is, the number of cigarettes per day, age of start of smoking, duration of smoking and end inspiratory breath holding (EIBH) were recorded. Among them $92(71 \%)$ had leg pain on exertion and rest while $38(29 \%)$ had no exertional leg pain. Participants in the leg pain on exertion and rest group had a higher prevalence of co-morbidities associated with intermittent claudication than those with no leg pain. of cigarettes per day, duration of smoking, end inspiratory breath holding in seconds are taken into consideration (Table 2). Intermittent claudication was more in the age group of 51-60 years and least in 31-40 years. In 10 cases, intermittent claudication was not present in the age group of 31-40 years (Table 3).

Intermittent claudication in non-smokers was more in the age group of $61-70$ years $(20 \%), 10 \%$ in the age group of $51-$ 60 years and absent in the age group of 31-50 years (Table $4)$. Intermittent claudication was not seen in age group of

Table 1: Distribution of subjects by smoking and age

\begin{tabular}{|c|c|c|c|c|}
\hline & $31-40$ yrs & $41-50$ yrs & $51-60$ yrs & $61-70 \mathrm{yrs}$ \\
\hline 1. Non smokers & 15 & 5 & 10 & 10 \\
\hline 2. Ex-smokers & Nil & Nil & 5 & 2 \\
\hline 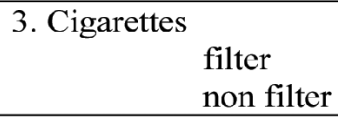 & $\begin{array}{l}10 \\
4 \\
\end{array}$ & $\begin{array}{l}23 \\
4 \\
\end{array}$ & $\begin{array}{l}23 \\
7 \\
\end{array}$ & $\begin{array}{l}5 \\
7 \\
\end{array}$ \\
\hline 4. Pipe \& cigar & Nil & Nil & Nil & Nil \\
\hline 5. Mixed & Nil & Nil & Nil & Nil \\
\hline Total & 29 & 32 & 45 & 24 \\
\hline
\end{tabular}

Table 2: Mean values in each age groups

\begin{tabular}{|l|l|l|l|l|}
\hline & $31-40$ yrs & $41-50$ yrs & $51-60$ yrs & $61-70$ yrs \\
\hline Age of starting smoking (yrs) & $21.6 \pm 4.9$ & $24.0 \pm 3.6$ & $25.2 \pm 3.4$ & $25.4 \pm 4.5$ \\
\hline No. of cigarettes & $13.2 \pm 4.2$ & $14.4 \pm 3.9$ & $12.7 \pm 2.1$ & $14.2 \pm 4.2$ \\
\hline $\begin{array}{l}\text { Duration of smoking } \\
\text { (yrs) }\end{array}$ & $13.2 \pm 3.9$ & $21.0 \pm 3.8$ & $28.1 \pm 3.9$ & $39.6 \pm 6.7$ \\
\hline $\begin{array}{l}\text { End inspiratory breath hold } \\
\text { (seconds) }\end{array}$ & 30 & 20 & 30 & 20 \\
\hline
\end{tabular}

Table 3: Occurrence of intermittent claudication (IC) among smokers group

\begin{tabular}{|c|c|c|c|c|}
\hline & \multicolumn{4}{|c|}{ Smokers total: 90} \\
\hline & $31-40$ yrs & $41-50 \mathrm{yrs}$ & $51-60$ yrs & $61-70$ yrs \\
\hline $\begin{array}{l}\text { IC present } \\
\text { Total: } 80\end{array}$ & $4(4.4 \%)$ & $27(30 \%)$ & $35(38.9 \%)$ & $14(15.5 \%)$ \\
\hline $\begin{array}{l}\text { IC not present } \\
\text { total: } 10\end{array}$ & $4(4.4 \%)$ & $3(3.33 \%)$ & $2(2.22 \%)$ & $1(1.11 \%)$ \\
\hline
\end{tabular}

Compared with controls, walking impairment was seen more in the typical exertional leg pain group with symptoms like pain, aching or cramps in the calves/buttocks; pain or aching in thighs; pain, stiffness and aching in lower-extremity joints (knee/ankle/hip) and weakness in one or both legs. In the 6minute walk, participants in the control group were less likely to stop and achieved a greater distance when compared with the intermittent claudication group. The exertional leg pain group had a slower walking velocity when compared with the control group.

The youngest subject in the study group was aged 31 years and the oldest aged 70 years (Table 1). The mean age of the study group was 48.56 years and of control group was 48.96 years. The parameters like age of starting smoking, number
$31-50$ years $(70 \%)$ and there incidence increases as the age advances as is seen in the age group of 61-70 years (20\%).

Exposure rate:

Intermittent claudication present: $80 \times 100=86 \%$; (92)

Intermittent claudication not present: $10 \times 100=26 \%$; (38)

Relative risk $=$ incidence among smokers $=2.96$ incidence among nonsmokers

Smokers were at higher risk of developing intermittent claudication than the non-smokers (Table 4, 5). Among the non-smokers, elderly patients were at higher risk of developing intermittent claudication. There was high correlation between smoking and intermittent claudication (Pearson's correlation coefficient $\mathrm{P}<0.01$ ). 
Table 4: Occurrence of intermittent claudication among non-smokers

\begin{tabular}{|l|l|l|l|l|}
\hline & Non-smokers total: 40 & \multicolumn{5}{l|}{} \\
\hline & $31-40$ yrs & $41-50$ yrs & $51-60$ yrs & $61-70$ yrs \\
\hline IC present total: 12 & Nil & Nil & $4(10 \%)$ & $8(20 \%)$ \\
\hline $\begin{array}{l}\text { IC not present } \\
\text { total: } 28\end{array}$ & $10(25 \%)$ & $10(25 \%)$ & $6(15 \%)$ & $2(5 \%)$ \\
\hline
\end{tabular}

Table 5: Intermittent claudication in different age groups

\begin{tabular}{|lc|l|l|l|l|}
\hline & & $31-40$ yrs & $41-50$ yrs & $51-60$ yrs & $61-70$ yrs \\
\hline Smokers. & SCLI & $28.5 \%$ & $92.5 \%$ & $91 \%$ & $78 \%$ \\
& CLI & Nil & $7.4 \%$ & $8 \%$ & $21 \%$ \\
\hline \multirow{2}{*}{ Non-smokers. } & SCLI & Nil & Nil & $33.3 \%$ & $50 \%$ \\
& CLI & Nil & Nil & Nil & $16.6 \%$ \\
\hline
\end{tabular}

Depending on severity subjects are categorized into

1. Subcritical limb ischaemia. SCLI (grade I)

2. Critical limb ischaemia. CLI( grade II )

The exposure rate of occurrence of intermittent claudication in the overall study group is nearly $86 \%$ whereas that in smokers is $88 \%$ and that in non-smokers is just $26 \%$. This means the relative risk of disease was 2.96 times more in the smokers than the non-smokers.

\section{Discussion}

In this study, age range was from 30 to 70 years. The peak incidence of intermittent claudication was in the age group of after 40 years. The age of starting of smoking was nearly $24.4 \pm 3.6$ in all age groups. The number of cigarettes in each group on average was $13 \pm 4$ per day. The duration of smoking on an average was $24 \pm 2$ years. And end inspiratory breath holding on an average is 25 seconds. So, all these factors play a very important role in the development of intermittent claudication. Earlier the age of starting smoking, more the number of cigarettes, longer the duration of smoking and longer the end inspiratory breath holding, the more the risk of developing intermittent claudication. Based on the questionnaire, intermittent claudication was found prevalent in only $92(71 \%)$ of the total 130 participants included in study. Among 90 smokers, 80 (88\%) had the classic symptom of intermittent claudication which started in third decade of life. Whereas out of 40 non-smokers, only 12 (30\%) had intermittent claudication which started after fifth decade of life. This means the incidence rate of disease was 2.96 times more in the smokers than the non-smokers.

The chief pharmacological active ingredient in tobacco is nicotine (acute effects) and tars (chronic effects). Effects of nicotine on cardiovascular system are similar to sympathetic stimulation. It causes vasoconstriction in skin and vasodilatation in muscle, tachycardia and rise of blood pressure, increase in plasma noradrenalin, ventricular extra systole may occur, cardiac output and oxygen consumption increases. It increases atherosclerotic narrowing and platelet adhesiveness.

The finding of the present study is in conformity with the earlier studies done by many that are discussed below.

Epidemiological studies indicate that upto 5\% of men and $2.5 \%$ of women above 60 years of age have symptoms of intermittent claudication. ${ }^{3}$ It affects $1-2 \%$ of the population under 60 years of age, $3-4 \%$ of persons aged 60 to 70 and over $5 \%$ of people over 70 . Leg pain occurs in one leg in $40 \%$ of patients and in both legs in $60 \%$ of patients. Lower extremity peripheral arterial disease (PAD) affects $18 \%$ of men and women after 55 years of age in general medical practices. ${ }^{4}$ Peripheral arterial disease is associated with a 5 to 6-fold increased risk of cardiovascular morbidity and death. $^{5}$

The American Heart Association estimates that as many as 8 to 12 million Americans have PAD and that nearly 75 percent of those with PAD are symptomatic. ${ }^{6}$ The prevalence of lower-extremity PAD based on ankle-brachial blood pressure ratios is approximately 10 to 20 percent of community-dwelling individuals aged 65 and older and 18 to 29 percent of patients aged 50 and older in general medical practices. Severe critical leg ischemia affects fewer than 1 million adults in the United States. ${ }^{7,824}$

Bowlin SJ, Medalie JH studied the epidemiology of Intermittent Claudication in middle-aged men. A total of 360 previously healthy men developed intermittent claudication for a crude 5-year incidence rate of 43.1/1,000 $(360 / 8,343)$ or a crude annual incidence of $8.6 / 1,000 .^{9}$

Criqui MH, Fronek A, Barrett-Connor E studied the prevalence of peripheral arterial disease in a defined population. They used four highly reliable, sophisticated noninvasive tests (segmental blood pressure, flow velocity by Doppler ultrasound, postocclusive reactive hyperemia, 
and pulse reappearance half-time) to assess the prevalence of large-vessel peripheral artery disease and small-vessel peripheral artery disease in an older (average age 66 years) defined population of 613 men and women. ${ }^{10}$

Murabito JM, D'Agostino RB, Silbershatz H developed an intermittent claudication risk profile. The intermittent claudication risk profile allows physicians to identify highrisk individuals during a routine office visit and can be used to educate patients about modifiable risk factors, particularly smoking and blood pressure. Improved compliance with risk factor modification strategies may result in a beneficial impact on survival. ${ }^{11}$ Many others studied diagnosis and treatment of chronic arterial insufficiency of the lower extremities. They showed association between smoking and lower extremity arterial disease may, in fact, be even stronger than between smoking and coronary heart disease, with relative risk ratios ranging from 1.7 to 7.5 (Our study showed relative risk of 2.96). Based on these observations, interventions to decrease or eliminate cigarette smoking have long been advocated for patients with lower extremity arterial disease. $^{12,13}$

Ugurlu S, Seyahi S, Yazici H assessed the prevalence of angina, myocardial infarction and intermittent claudication by Rose questionnaire among patients with Behcet's syndrome. The prevalence of claudication was significantly more frequent only among the male patients (19/136 vs. 2/ $74, \mathrm{P}=0.008)$. Male patients with vascular involvement had more claudication $(15 / 67)$ than those without $(4 / 69)(\mathrm{P}<$ $0.006) .{ }^{14}$

Compared with patients without peripheral artery disease, diabetes mellitus and a history of smoking at least one pack of cigarettes per day were significantly associated with symptomatic peripheral artery disease. Diabetes mellitus combined with heavy smoking showed the highest predicted value positive (15\%) and the highest specificity (92\%). A lack of both demonstrated low rates for predicting asymptomatic PAD (predicted value positive, 1\%). ${ }^{15-17}$

Girolami showed the improvement of intermittent claudication with physical training, smoking cessation, pentoxifylline, or nafronyl. ${ }^{18}$

Fowkes FG in their study showed the measurement of atherosclerotic peripheral arterial disease in epidemiological surveys. ${ }^{19}$

Rose GA, Blackburn H, Gillum RF used WHO/Rose Questionnaire on ischemic heart pain and intermittent claudication by epidemiological field surveys. Several population studies have shown, however, that it is only moderately sensitive (60-68\%), although highly specific (90$100 \%$ ). They concluded that in this particular situation the questionnaire diagnosis showed reasonable (about 83\%) sensitivity and high specificity as compared to diagnosis by physicians. The physicians' interviews occupied 15 minutes each, as compared to about one minute for the questionnaire. ${ }^{20,21}$

Many studied the sensitivity, specificity and predictive value of traditional clinical evaluation of peripheral disease results from noninvasive testing in a defined population. ${ }^{22}$ All these studies showed that, compared with subjects without claudication, the claudication cases suffered increased mortality rates due to coronary heart disease and cerebrovascular disease, but the mortality rate due to noncardiovascular causes was not increased. The latter can be usefully incorporated in cardiovascular risk assessment and screening programs. ${ }^{23,24}$

\section{Conclusions}

Smoking increases the risk for development of intermittent claudication by more than $80 \%$. Risk factors associated with peripheral artery disease include older age, diet, nutritional status, hormonal status, cigarette smoking, diabetes mellitus, hypertension, hypercholesterolemia, and (possibly) genetic factors etc. There is a wide range of leg symptoms in persons with peripheral artery disease beyond that of classic intermittent claudication. Co-morbid disease may contribute to these symptoms in peripheral artery disease. Functional impairments are found in every peripheral artery disease symptom group, and the degree of functional limitation varies depending on the type of leg symptom. The intermittent claudicating risk profile allows physicians to identify high-risk individuals during a routine office visit and can be used to educate patients about modifiable risk factors, particularly smoking and blood pressure. Improved compliance with risk factor modification strategies may result in a beneficial impact on survival.

\section{Acknowledgements}

My sincere thanks to, Principal of Sri Devaraj Urs medical university for permitting me to prepare this paper; faculty members of department of physiology for their kind cooperation and Dr. Arun Kumar S. Bilodi, professor and HOD of Anatomy, Hassan Institute of Medical sciences, Hassan for his kind cooperation.

\section{References}

1. Meijer WT, Grobbee DE, Hunink MG, Hofman A, Hoes AW. Determinants of peripheral arterial disease in the elderly: the Rotterdam study. Arch Intern Med. 2000 Oct 23;160(19):2934-8. 
2. Bloomfield P, Bradbury A, Grubb NR, Newby DE. Vascular diseases. In: Boon NA, Colledge NR, Walker BR, Hunter JAA, editors. Davidson's principles and practice of medicine. 20th ed. New Delhi, India: Reed Elsevier India Private Limited, Sri Pratap Udyog; 2006. p. 601-4.

3. Seyed MS, Seyedeh MN, Mansoor R, et al. Agreement between ABI (ankle brachial index) and USD (ultrasound duplex scanning) in symptomatic peripheral arterial disease patients. The journal of Tehran University Heart Center. 2008;3(1):35-8.

4. Leng GC, Fowkes FG, Lee AJ, Dunbar J, Housley $\mathrm{E}$, Ruckley CV. Use of ankle brachial pressure index to predict cardiovascular events and death: a cohort study. BMJ. 1996 Dec 7;313(7070):1440-4.

5. Criqui MH, Langer RD, Fronek A, Feigelson HS, Klauber MR, McCann TJ, et al. Mortality over a period of 10 years in patients with peripheral arterial disease. N Engl J Med. 1992 6;326(6):381-6.

6. American Heart Association. Diseases and conditions. PAD quick facts. [Online]. [cited $2004 \mathrm{Jul}$ 9]. Available from: URL:http://www.americanheart.org/ presenter.jhtml?identifier $=3020242$

7. Fowkes FG, Housley E, Cawood EH, Macintyre CC, Ruckley CV, Prescott RJ. Edinburgh Artery Study: prevalence of asymptomatic and symptomatic peripheral arterial disease in the general population. Int $\mathbf{J}$ Epidemiol. 1991;20(2):384-92.

8. Meijer WT, Hoes AW, Rutgers D, Bots ML, Hofman A, Grobbee DE. Peripheral arterial disease in the elderly: The Rotterdam Study. Arterioscler Thromb Vasc Biol. 1998;18(2):185-92.

9. 9) Bowlin SJ, Medalie JH, Flocke SA, Zyzanski SJ, Goldbourt U. Epidemiology of intermittent claudication in middle-aged men. Am J Epidemiol. 1994;140(5):418-30.

10. Criqui MH, Fronek A, Barrett-Connor E, Klauber MR, Gabriel S, Goodman D. The prevalence of peripheral arterial disease in a defined population. Circulation. 1985;71(3):510-5.

11. Murabito JM, D'Agostino RB, Silbershatz H, Wilson WF. Intermittent claudication. A risk profile from The Framingham Heart Study. Circulation. 1997 Jul 1;96(1):44-9.

12. Weitz JI, Byrne J, Clagett GP, Farkouh ME, Porter JM, Sackett DL, et al. Diagnosis and treatment of chronic arterial insufficiency of the lower extremities: a critical review. Circulation. 1996;94(11):3026-49.
13. Asgeirsdóttir LP, Agnarsson U, Jónsson GS. Lower extremity blood flow in healthy men: effect of smoking, cholesterol, and physical activity-a Doppler study. Angiology. 2001;52(7):437-45.

14. Ugurlu S, Seyahi E, Yazici H. Prevalence of angina, myocardial infarction and intermittent claudication assessed by Rose Questionnaire among patients with Behcet's syndrome. Rheumatology (Oxford). 2008; 47(4):472-5.

15. Eason SL, Petersen NJ, Suarez-Almazor M, Davis B, Collins TC. Diabetes mellitus, smoking, and the risk for asymptomatic peripheral arterial disease: whom should we screen? J Am Board Fam Pract. 2005;18(5):355-61.

16. Agarwal S. The association of active and passive smoking with peripheral arterial disease: results from NHANES 1999-2004. Angiology. 2009;60(3):335-45.

17. Dickinson KJ, Cockbain AJ, MacDonald W, Shah M, Homer-Vanniasinkam S. The physiological effects of short-term smoking cessation in claudicants. Angiology. 2009;60(2):159-63.

18. Girolami B, Bernardi E, Prins MH, Ten Cate JW, Hettiarachchi R, Prandoni P, et al. Treatment of intermittent claudication with physical training, smoking cessation, pentoxifylline, or nafronyl: a metaanalysis. Arch Intern Med. 1999;159(4):337-45.

19. Fowkes FG. The measurement of atherosclerotic peripheral arterial disease in epidemiological surveys. Int J Epidemiol. 1988 ;17(2):248-54.

20. Rose GA, Blackburn H, Gillum RF, Princes RJ. Cardiovascular Survey Methods. 2nd ed. Geneva: World Health Organization; 1982. p. 173-5.

21. Rose GA. The diagnosis of ischaemic heart pain and intermittent claudication in field surveys. Bull World Health Organ. 1962;27:645-58.

22. Criqui MH, Fronek A, Klauber MR, Barrett-Connor E, Gabriel S. The sensitivity, specificity, and predictive value of traditional clinical evaluation of peripheral arterial disease: results from noninvasive testing in a defined population. Circulation. 1985 ;71(3):516-22.

23. Smith GD, Shipley MJ, Rose G. Intermittent claudication, heart disease risk factors, and mortality. The Whitehall Study. Circulation. 1990 ;82(6):1925-31.

24. U.S. Preventive Services Task Force. Guide to Clinical Preventive Services. 2nd ed. Washington DC: Office of Disease Prevention and Health Promotion; 1996. 